\title{
Continuous venovenous hemodiafiltration using cytokine-adsorbing hemofilters as adjuvant therapy for anaerobic descending necrotizing mediastinitis: a case report
}

\author{
Dijana Popevski, Magdelena Popovska-Cvetkova, Katerina Ignevska, Rodney A. Rosalia and Zan Mitrev
}

\begin{abstract}
Background: We describe a combinatorial intensive care approach and discuss the critical factors that allowed us to successfully manage a life-threatening case of acute anaerobic septic shock triggered by descending necrotizing mediastinitis.

Case presentation: We admitted a 38-year-old critically ill Kosovar Albanian man to our intensive care unit because of clinical manifestations of severe sepsis. His condition had worsened in the previous 2 weeks following unsuccessful antibiotic therapy for tonsillitis complicated by retropharyngeal abscesses. Computed tomography and intraoperative observations identified abscesses in the anterior and middle mediastinum regions and the distal part of the neck, directly on the border with the left lobe of the thyroid gland. Cultures indicated infections with a-hemolytic Streptococcus and Clostridium species: High procalcitonin and lactate levels, blood gas analysis, poor peripheral capillary oxygen saturation, and severe hemodynamic instability pointed to a case of acute septic shock. The entire treatment consisted of an aggressive antibiotic regimen, transthoracic and mediastinal surgical evacuation of the abscess, vacuum sealing drainage with a pleural chest tube, continuous venovenous hemodiafiltration using cytokine-adsorbing hemofilters, and extracorporeal blood hyperoxygenation.

Conclusions: Efficient treatment of severe anaerobic sepsis resulting from descending necrotizing mediastinitis should build on a multidisciplinary approach. In support of first-line therapies with targeted antibiotics and surgical debridement, clinicians should consider alternative therapies such as continuous venovenous hemodiafiltration with cytokine-adsorbing hemofilters and hyperoxygenation.
\end{abstract}

Keywords: Descending necrotizing mediastinitis (DNM), Anaerobic septic shock, Extracorporeal blood oxygenation

\section{Introduction}

Descending necrotizing mediastinitis (DNM) is an acute, life-threatening disease caused by infections originating in the head and neck area. Immediate antibiotherapy, control of the source of infection, and surgical debridement of the affected tissue are the cornerstones of treatment [1]. The localization of the infection directly influences the mortality rate [2], and failure to control the microbial metastasis can lead to hemodynamic impairment, multiorgan failure, and septic shock [3-5].

\footnotetext{
* Correspondence: zan@zmc.mk

Zan Mitrev Clinic, Skopje, Republic of Macedonia
}

A negative factor in the treatment of DNM-induced septic shock is the presence of polymicrobial anaerobic strains [6], particularly in those cases including clostridial species $[7,8]$. Prognosis is poor once anaerobic septic shock is established $[9,10]$, as a consequence of the complex underlying disease, the source of infection [11], and the evolution of anaerobes toward antibiotic resistance [12].

This case report details our early initiation strategy of continuous renal replacement therapy (CRRT) combined with extracorporeal blood purification and hyperoxygenation in the management of sepsis. Furthermore, our work highlights the importance of multidisciplinary intensive care in the

(c) The Author(s). 2019 Open Access This article is distributed under the terms of the Creative Commons Attribution 4.0 International License (http://creativecommons.org/licenses/by/4.0/), which permits unrestricted use, distribution, and 
successful management of a 38-year-old man with acute anaerobic septic shock due to DNM.

\section{Case presentation}

We admitted a 38-year-old Kosovar Albanian man, an entrepreneur, to our emergency department in a critical state. He has never smoked and has no prior medical history or family history of illnesses. He reported enjoying an occasional alcoholic drink.

His symptoms had started after physical exercise 2 weeks before. He was then diagnosed at a local clinic with tonsillitis (lacunar angina) complicated with several retropharyngeal abscesses. He was prescribed first-line oral antibiotics; the treatment failed, and his clinical condition drastically worsened in the following days, which prompted the referral to our hospital.

On clinical examination, he was tachycardic with a heart rate of 130 beats/min and blood pressure of 100/
$70 \mathrm{mmHg}$, heavily somnolent with a Glasgow Coma Scale score of 10, and hypoxemic and cyanotic with a ratio of partial pressure of arterial oxygen to fraction of inspired oxygen $\left(\mathrm{PaO}_{2} / \mathrm{FiO}_{2}\right)$ of $66 \mathrm{mmHg}$ and a mean arterial pressure of $82 \mathrm{mmHg}$. His peripheral capillary oxygen saturation was $75 \%$ while wearing a $6-\mathrm{L} \mathrm{O}_{2}$ mask. We detected abnormal bronchial breath sounds and reduced airflow in the lower lobes.

Computed tomography (CT) indicated lymphadenopathy, inflammation, and fluid collection in the mediastinum accompanied by significant fibrin depositions (Fig. 1a, b). Abscesses were observed in the anterior and middle mediastinal regions (Fig. 1b, c) and the distal part of the neck, directly on the border with the left lobe of the thyroid gland (Fig. 1c, d). Other than weakness, the patient had no signs of any physical complications; moreover, neurological examinations did not reveal major abnormalities. The
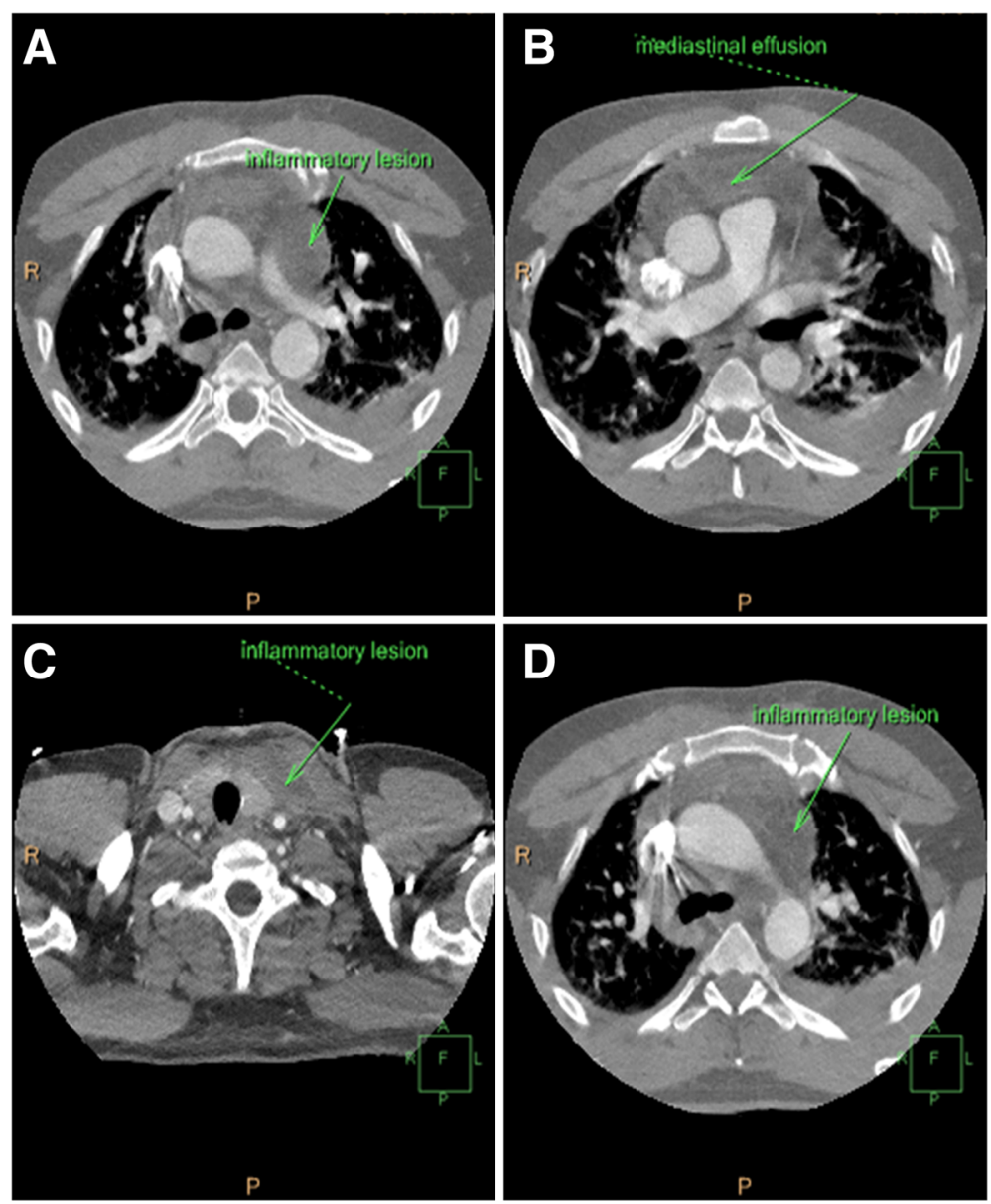

Fig. 1 Preoperative computed tomographic $(\mathrm{CT})$ scans of a critically ill patient displaying clinical signs of descending necrotizing mediastinitis. a CT scan showing increased density of the middle mediastinal space. Fluid collections in mediastinum and lymphadenopathy are shown (arrow). $\mathbf{b}$ CT scan showing increased density of the mediastinal space, fluid collections, and lymphadenopathy with bilateral pleural effusions (arrow). c CT scan showing fluid collections, as well as abscess formation left of the thyroid gland and ventral of the carotid arteries (arrow). $\mathbf{d}$ CT scan showing increased density of the middle mediastinal space, fluid collections in mediastinum, and lymphadenopathy (arrow) 
patient had slightly delayed motor responses and a normal pupil size and reaction to light, but his speech was incomprehensible.

The patient was admitted to the intensive care unit (ICU), where he was sedated (propofol, induction dose $2.0 \mathrm{mg} / \mathrm{kg}$, maintenance dose $0.07-0.21 \mathrm{mg} / \mathrm{kg} /$ $\mathrm{hr}$ ), intubated, and placed on mechanical ventilation with bilevel positive airway pressure $\mathrm{FiO}_{2}$ of $70 \%$. We administered intravenous aminophylline $250 \mathrm{mg}$ every $12 \mathrm{hr}$. As a gastroprotective therapy, we used ranitidine $50 \mathrm{mg}$ every $8 \mathrm{hr}$. The continuous fluid therapy consisted of $200 \mathrm{ml} / \mathrm{hr} \mathrm{NaCl} 0.9 \%$ and $50 \mathrm{ml} / \mathrm{hr}$ glucose $5 \%$ for the first $24 \mathrm{hr}$. We initiated parenteral nutrition using Aminoven 10\% (40 ml/hr; Fresenius $\mathrm{Kabi}, \mathrm{Graz}$, Austria) and a fat emulsion $(20 \mathrm{ml} / \mathrm{hr}$; INTRALIPID ${ }^{\circ} 20 \%$; Fresenius Kabi).

We collected blood, urine, and tracheal aspirate samples for microbiological analysis (Additional file 1) . In anticipation of the definitive culture results, we administered broad-spectrum antibiotics (Fig. 2). The patient was oliguric at this stage, with a urine output less than $50 \mathrm{ml}$ in the first $2 \mathrm{hr}$ in the ICU; furthermore, his creatinine $(109.7 \mu \mathrm{mol} / \mathrm{L})$, urea $(10.6 \mathrm{mmol} /$
L), and glomerular filtration rate (GFR) $(69 \mathrm{ml} / \mathrm{min} /$ $1.73 \mathrm{~m}^{2}$ ) pointed to mildly reduced kidney function (Fig. 3).

On the basis of these findings, CRRT was indicated. We placed a 12-French double-lumen catheter in the right femoral vein to establish vascular access. Bearing in mind the likelihood of a systemic infection, we treated the patient with continuous venovenous hemodiafiltration with cytokine-adsorbing filters (CVVHDF-CAH) (PRISMAFLEX oXiris ${ }^{\circ}$ filter; Baxter, Deerfield, IL, USA) set at a high hemofiltration rate of $35 \mathrm{ml} / \mathrm{kg} / \mathrm{hr}$. We exchanged the filters every $24 \mathrm{hr}$.

We next performed an urgent median sternotomy to remove the abscesses and purulent fluid. Tissue samples from the mediastinum and thymic area were collected for microbiological and histopathological analysis. We performed vacuum-assisted wound closure, and we replaced the drain every $48 \mathrm{hr}$.

The surgical intervention failed to revert his deteriorating condition. He became febrile $\left(38.9^{\circ} \mathrm{C}\right)$ and hemodynamically unstable (Table 1 ). At this stage, his serum lactate was $6.3 \mathrm{mmol} / \mathrm{L}$, and blood gas analysis (BGA) revealed acidosis. Because of his hemodynamic

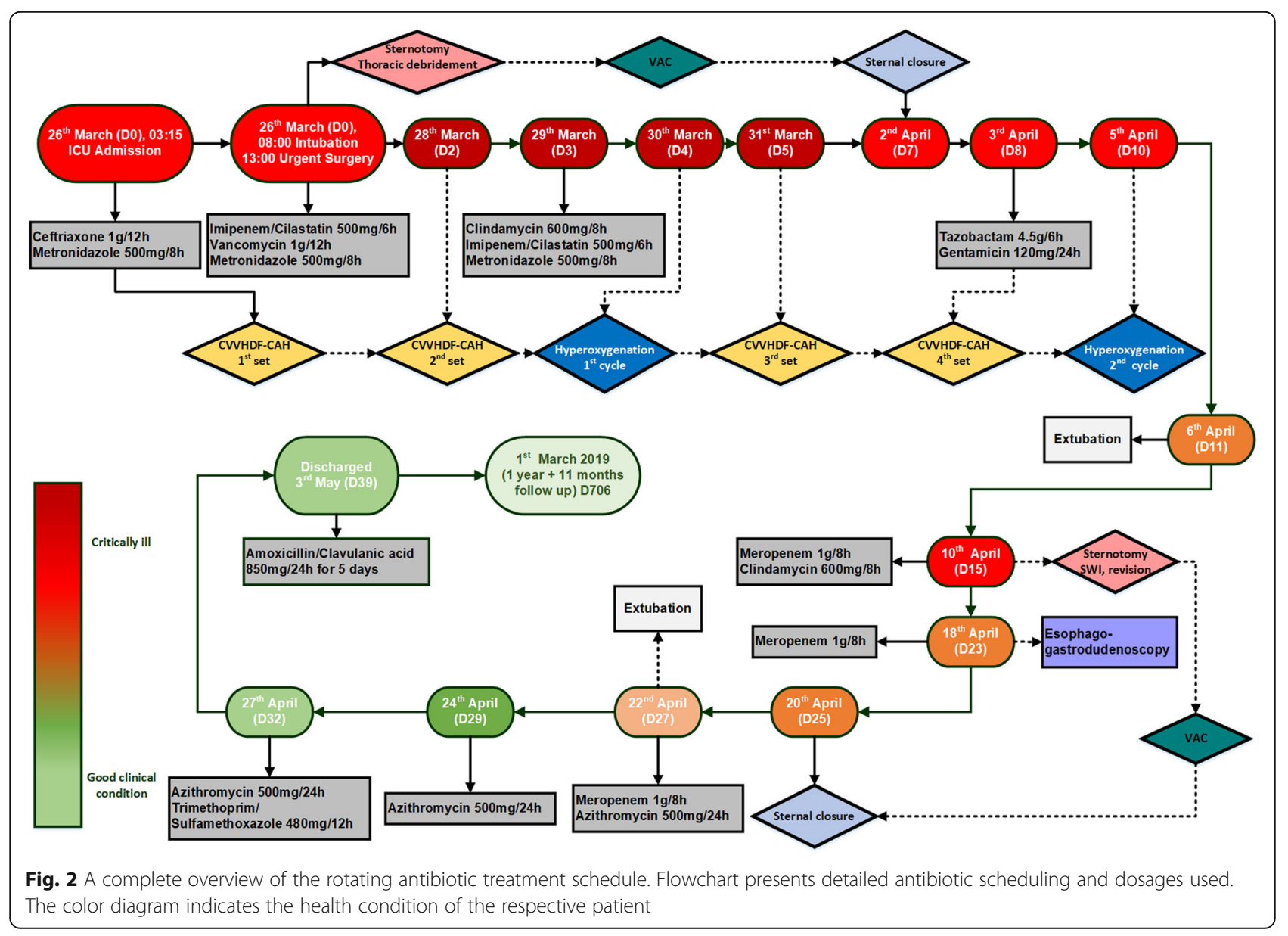




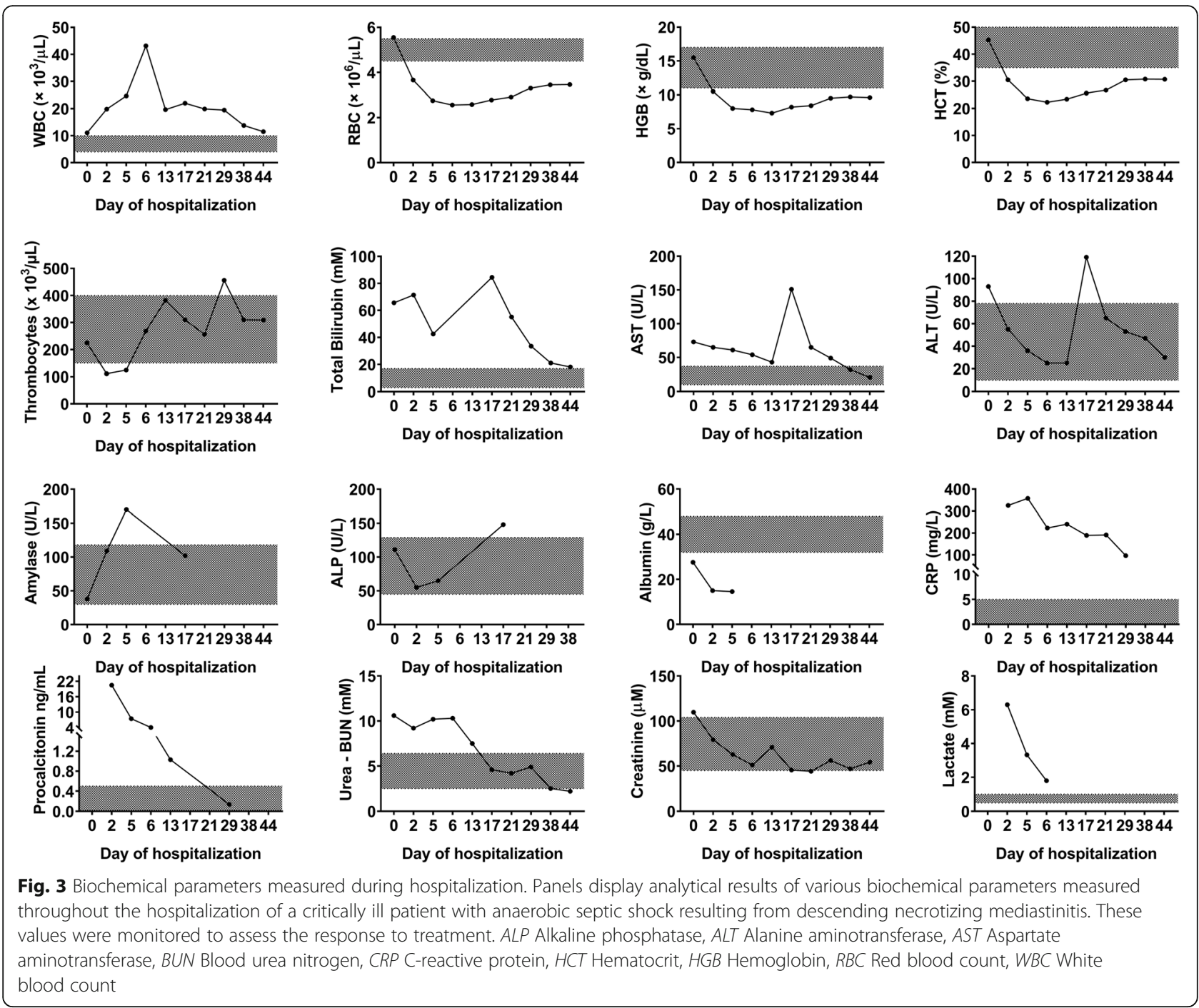

instability, we administered norepinephrine, but increasing the dosage from $0.2 \mathrm{mg} / \mathrm{hr}$ to $1 \mathrm{mg} / \mathrm{hr}$ over the next $48 \mathrm{hr}$ was unsuccessful in reverting his poor systemic vascular resistance (FloTrac/Vigileo ${ }^{\text {Tw }}$ monitoring; Edwards Lifesciences, Irvine, CA, USA) of $\leq$ $700 \mathrm{dyn} / \mathrm{s} / \mathrm{cm}^{5}$.
His clinical condition further deteriorated. He developed a high fever $\left(40^{\circ} \mathrm{C}\right)$ overnight, and his Simplified Acute Physiology Score II of 63 points suggested a poor prognosis.

Histopathological analysis revealed the presence of acute suppurative inflammation in the thymic and parathymic

Table 1 Hemodynamic monitoring of a patient with descending necrotizing mediastinitis-induced anaerobic septicemia during the first 7 days of hospitalization

\begin{tabular}{|c|c|c|c|c|c|c|c|c|}
\hline $\begin{array}{l}\text { Time point of } \\
\text { hospitalization }\end{array}$ & $\begin{array}{l}\text { Mean arterial } \\
\text { pressure }(\mathrm{mmHg})\end{array}$ & $\begin{array}{l}\text { Heart rate } \\
\text { (beats/min) }\end{array}$ & $\begin{array}{l}\text { Cardiac } \\
\text { output (L/min) }\end{array}$ & $\begin{array}{l}\text { Cardiac index } \\
\left(\mathrm{L} / \mathrm{min} / \mathrm{m}^{2}\right)\end{array}$ & $\begin{array}{l}\text { Stroke } \\
\text { volume (ml/beat) }\end{array}$ & $\begin{array}{l}\text { Stroke volume } \\
\text { variation (\%) }\end{array}$ & $\begin{array}{l}\text { Systemic vascular } \\
\text { resistance }\left(\mathrm{dyn} / \mathrm{s} / \mathrm{cm}^{5}\right)\end{array}$ & $\begin{array}{l}\text { Base } \\
\text { excess } \\
(\mathrm{mmol} / \mathrm{L})\end{array}$ \\
\hline Day 0 & 82 & 130 & ND & ND & ND & ND & ND & ND \\
\hline Day 1 & 50 & 130 & 4.0 & 1.8 & 58 & 20 & $\leq 550$ & -9.1 \\
\hline Day 4 & 55 & 120 & 3.8 & 1.7 & 50 & 23 & 600 & -6.8 \\
\hline Day 6 & 70 & 110 & 4.3 & 2.0 & 60 & 10 & 800 & 3.4 \\
\hline
\end{tabular}

Abbreviation: ND No data

Extracorporeal blood hyperoxygenation was performed on days 4 and 10 


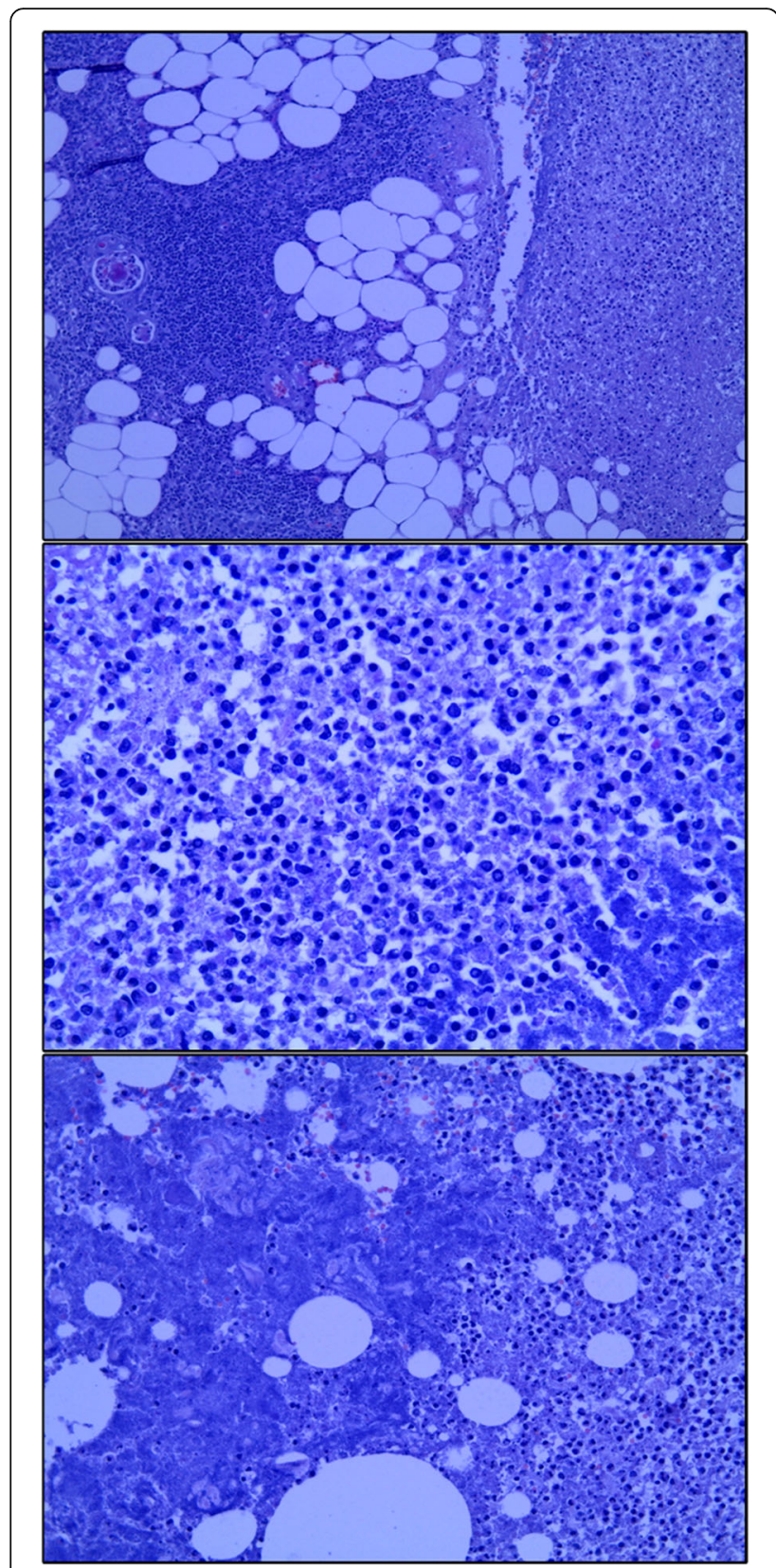

Fig. 4 Histopathological staining of the thymic and parathymic tissue. Thymic and parathymic tissue with necrotic debris, neutrophil apoptosis, and massive infiltration of lymphocytes. Hassall's

corpuscles are shown. Lymphocyte aggregates are present in the fat of the involuted thymic tissue. The surrounding connective tissue is characterized by inflammation and purulent (suppurative) exudate consisting of dead neutrophils, fibrinogen, erythrocytes, and colonies of bacteria

tissue (Fig. 4), characterized by lymphocytic, neutrophilic infiltration and pus formation. Microbiological analysis of the wound samples revealed gram-positive cocci, identified as $\alpha$-hemolytic Streptococcus; furthermore, the anaerobic cultures of the mediastinal tissue samples confirmed the growth of gram-positive bacilli of the Clostridium species.

We switched to a (rotating) antibiotic therapy according to the antibiogram or clinical observations. The detailed antibiotherapy timeline is shown in Fig. 2.

Collectively, the clinical manifestations and radiographic, biochemical (Fig. 3), microbiological, and histopathological examinations indicated a severe case of anaerobic sepsis resulting from DNM [13, 14].

The patient remained in critical condition on day 3 , with a fever of $40.1{ }^{\circ} \mathrm{C}$, hemodynamic impairment, acidosis, and lactate level of $3.3 \mathrm{mmol} / \mathrm{L}$ (Table 1 ). We commenced hyperalimentation to counter the patient's low serum albumin level $(14.6 \mathrm{~g} / \mathrm{L})$.

On day 4, the patient's $\mathrm{PaO}_{2} / \mathrm{FiO}_{2}$ ratio was $114 \mathrm{mmHg}$. A transthoracic echocardiogram revealed pleural effusion in the right costophrenic space. Because of the patient's worsening condition, we opted for extracorporeal blood oxygenation (EBOO) for $1 \mathrm{hr}$ to improve the peripheral oxygenation of $<90 \%$. EBOO was performed through the (same) right femoral vein catheter used for the CVVHDFCAH. We coinfused low-dose $\mathrm{O}_{3}, 10 \mu \mathrm{g} / \mathrm{ml}$ blood, and a bolus injection of $2 \mathrm{~g}$ of vitamin $\mathrm{C}$ to counter possible oxidative stress associated with hyperoxia. We also performed thoracentesis to remove $2800 \mathrm{ml}$ of purulent fluid.

Our approach improved the patient's clinical condition in the following $24 \mathrm{hr}$, gradually normalized his body temperature and biochemical parameters, and improved his BGA parameters; his $\mathrm{PaO}_{2}$ increased to $433 \mathrm{mmHg}$ from an initial $80 \mathrm{mmHg}$ (Table 1 and Fig. 3).

Consequently, we could decrease $\mathrm{FiO}_{2}$ to $50 \%$ while maintaining the $\mathrm{PaO}_{2}$ at $133.3 \mathrm{mmHg}$ and $\mathrm{O}_{2}$ saturation at $98 \%$. The sternum was closed on day 7 , and the norepinephrine dosage was lowered to $0.06 \mathrm{mg} / \mathrm{hr}$. The patient was extubated on day 11.

His recovery was short-lived. He once again became febrile on day 15 . We observed a purulent secretion from the sternum that required an emergency median sternotomy, surgical debridement of necrotic tissue, and de novo vacuum-sealing drainage.

His overall clinical condition improved; nevertheless, he developed gastroesophageal bleeding on day 23. Via esophagogastroduodenoscopy, we identified a polypoid mass on the lateral wall of the esophagus measuring $10-15 \mathrm{~mm}$ in diameter. Pathological analysis of the biopsies confirmed squamous papilloma of the esophagus, inflammation, and ulceration.

The bleeding ceased upon the successful excision of the polypoid mass.

From day 24 onward, the patient's condition steadily improved. He was kept in the ICU on continuous respiratory support and physical therapy until follow-up culture results were negative. 
We performed the final vacuum sealing with definitive closure of the lesion on day 25 and extubation on day 27.

The patient was slightly dysphonic but otherwise in a decent health condition (Fig. 2), and he was discharged on day 39. Control CT evaluation 5 days after discharge confirmed a complete regression of the abscesses (Fig. 5).

The fully recovered patient presented for follow-up 1 year later in good mental and physical condition with no further complications.

\section{Discussion}

In this report, we describe a novel treatment approach for mediastinitis and anaerobic sepsis that includes our early initiation of a CVVHDF-CAH protocol, adjuvant blood purification using the modified AN69ST high-permeability membrane (oXiris $\left.{ }^{\circ}\right)$, and the use of intermittent extracorporeal blood hyperoxygenation. Furthermore, our work suggests a clinical benefit of the use of the oXiris ${ }^{\circ}$ membrane in the treatment of gram-positive bacterial infections, thus possibly paving the way for clinical use beyond gram-negative systemic infections.

Sepsis is characterized by an uncontrolled immune response to infections that may lead to life-threatening organ dysfunction and, in severe cases, death.

Advanced extracorporeal blood purification modalities that include cytokine and endotoxin removal capacity have been developed in the past decade as a potential therapy for critically ill patients with sepsis or those at high risk of developing sepsis and acute kidney injury.

Several extracorporeal blood purification techniques exist [15]. The use of the AN69ST membrane (oXiris ${ }^{\circ}$ ) [16] may offer advantages over other commonly used cytokine-adsorbing hemofilters because it effectively removes a broad spectrum of proinflammatory cytokines $[17,18]$.
However, the current evidence to support the use of extracorporeal blood purification approaches in humans is limited mostly to case series [19, 20]. Randomized controlled trials have generated conflicting results [21-26]. Consequently, routine clinical use is currently not advocated $[27,28]$.

Nevertheless, we hypothesize that the heterogeneity in clinical outcomes mirrors the lack of standardized CRRT protocols using blood purification modalities, for instance, the timing of CRRT initiation, CRRT duration, and differences in the type of hemofilter used [29-32].

At our clinic, we consider CVVHDF-CAH (oXiris ${ }^{\circ}$ ) for all hemodynamically unstable (oliguric) critically ill patients who show signs of an uncontrolled inflammatory syndrome (C-reactive protein $>40 \mathrm{mg} / \mathrm{ml}$ and procalcitonin $>0.5 \mathrm{ng} / \mathrm{ml}$ ) in combination with reduced GFR. These include patients suspected of systemic inflammatory response syndrome or sepsis.

With this case report, we present one of our most challenging cases of septic shock resulting from DNM. $\mathrm{DNM}$ is a rare but rapidly progressing life-threatening disease in which the mediastinal infection can quickly extend below the tracheal carina, followed by lethal septicemia if not diagnosed and managed in a timely and appropriate manner. In our patient's case, we suspected the DNM to be a complication of tonsillitis.

Kocher et al. and Palma et al. recently described their single-center experiences with DNM that signified the complex and heterogeneous clinical manifestation of the disease resulting in varying clinical outcomes [33-37].

Anaerobic infections are challenging in part because of the emergence of antibiotic-resistant strains [12], an unfortunate development especially in the Balkans [38].

The crude mortality associated with anaerobic bacteremia was shown to be $25 \%$ [6]. Polymicrobial infection is a known risk factor for death. Progressive infection is often
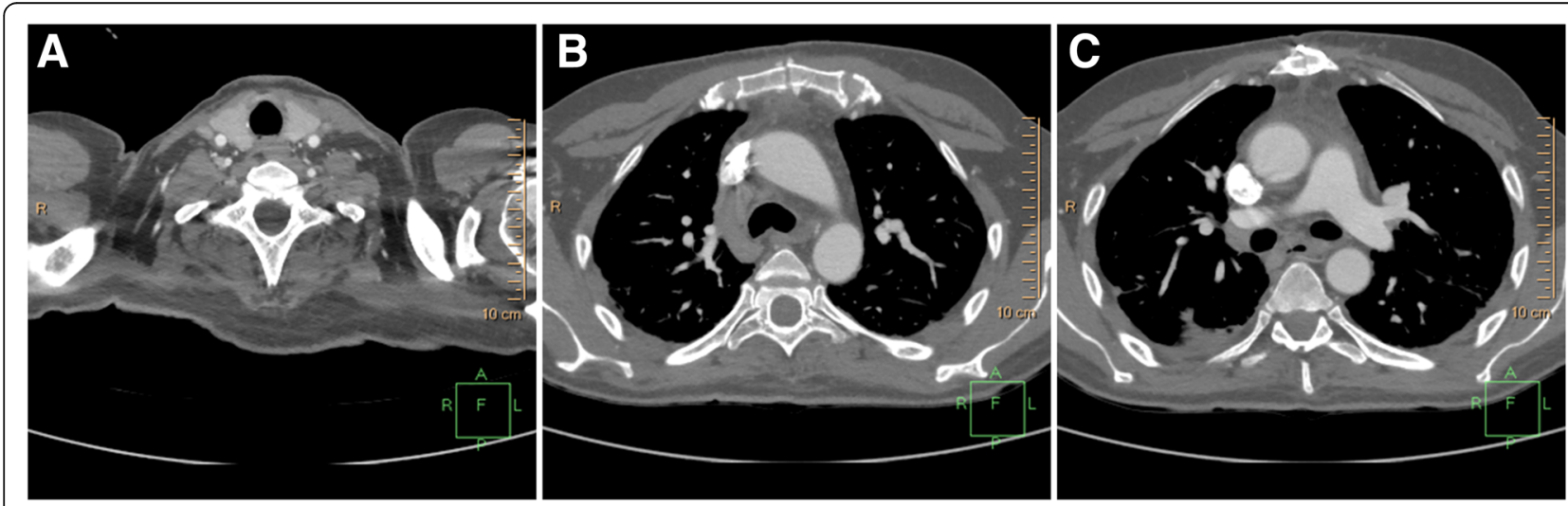

Fig. 5 Control computed tomographic analysis. a Control computed tomographic scan obtained on day 44 shows normal physiological findings indicating a complete regression of the abscess formation near the left lobe of the thyroid gland and ventral of the carotid arteries. $\mathbf{b}$ and $\mathbf{c}$ Fibrous adhesion in the middle mediastinal space 
detrimental; uncontrolled anaerobic sepsis carries a high 30-day mortality rate of 51\% [3-5].

The European Association for Cardio-Thoracic Surgery recently published its updated recommendations on the management of DNM [1]. In agreement with these recommendations, we directly initiated an aggressive antibiotic treatment plan on suspicion of DNM that was rotated to counter possible antibiotic resistance. Antibiotherapy was followed by a targeted mediastinal surgical debridement of the necrotic tissue, vacuum-assisted wound closure, pleural and pericardial drainage, vasopressor support, and continuous mechanical ventilation.

Nonetheless, the recommended approach was unsuccessful; in these cases, we propose the use of adjuvant therapies in the management of DNM. Our patient presented with DNM and developed acute anaerobic septic shock as a consequence of coinfections by $\alpha-$ hemolytic Streptococcus and Clostridium species of an unknown source.

Clostridium species and $\alpha$-hemolytic Streptococcus induce epithelial cell necrosis, which triggers the release of proinflammatory cytokines and high mobility group protein B1 (HMGB1), a well-described danger-associated molecular pattern associated with sepsis [39, 40]. The AN69ST membrane has a superior adsorptive capacity for endotoxin, lipid A, and, importantly, HMGB1 [16].

Our patient likely benefited from the early use of CVVHDF-CAH $\left(\right.$ oXiris $^{\circ}$ ) set at a high filtration rate to achieve adequate removal of harmful proinflammatory mediators [19, 41-43]. Also, the use of intermittent extracorporeal blood hyperoxygenation [44] promotes peripheral tissue vascularization $[45,46]$.

In summary, our combination therapy was successful; the patient recovered completely after a lengthy hospitalization. He regularly communicates with our clinical staff via social media and reports a high quality of life.

\section{Conclusions}

Adjuvant therapy should be considered when first-line treatment regimens fail to control sepsis progression and organ failure.

Early initiation of CVVHDF-CAH may be critical to control systemic infection and provide adequate renal support. Moreover, extracorporeal hyperoxygenation could overturn tissue hypoxia by optimizing peripheral vascularization.

Nevertheless, in the absence of established guidelines advocating the use of CVVHDF-CAH and extracorporeal hyperoxygenation, we conclude that well-designed randomized controlled trials are warranted to guide clinical decision making. Perhaps the ongoing NCT02600312, NCT02398019, and NCT01779635 trials will provide a definitive answer on the clinical benefit of the oXiris ${ }^{\circ}$ system.
In summary, effective management of DNM-induced anaerobic septic shock benefits from a multidisciplinary approach that builds on the timely administration of antibiotics, skilled surgical intervention, and the use of adjuvant treatment modalities to support renal, pulmonary, and hemodynamic functioning.

\section{Additional file}

Additional file 1: Microbiology screening approach for wound swabs and blood cultures. (DOCX $15 \mathrm{~kb}$ )

\section{Abbreviations}

ALP: Alkaline phosphatase; ALT: Alanine aminotransferase; AST: Aspartate aminotransferase; BGA: Blood gas analysis; BUN: Blood urea nitrogen; CRP: Creactive protein; $C R R T$ : Continuous renal replacement therapy; $C$ : Computed tomography; CWHDF-CAH: Continuous venovenous hemodiafiltration using cytokine-adsorbing hemofilters; DNM: Descending necrotizing mediastinitis; EBOO: Extracorporeal blood oxygenation; GFR: Glomerular filtration rate; HCT: Hematocrit; HGB: Hemoglobin; HMGB1: High mobility group protein B1; ICU: Intensive care unit; $\mathrm{PaO}_{2} / \mathrm{FiO}_{2}$ : Ratio of partial pressure of arterial oxygen to fraction of inspired oxygen; RBC: Red blood count; WBC: White blood count

\section{Acknowledgements}

The authors thank Dr. Emil Stoicovski for his expertise and valuable assistance during the treatment of the patient.

\section{Authors' contributions}

$D P, M P C$, and ZM were responsible for patient care and devising the therapeutic approach. RR and DP wrote the manuscript. All authors read and approved the final manuscript.

\section{Funding}

Not applicable; no funding was received for this case report.

\section{Availability of data and materials}

Requests for all original data described in this case report can be submitted for evaluation upon request.

\section{Ethics approval and consent to participate}

The clinical practice and treatment procedures described in this case report were approved by the ethics committee of the Zan Mitrev Clinic. The extracorporeal oxygenation via the femoral vein as described in our report is still investigational.

\section{Consent for publication}

Written informed consent was obtained from the patient for publication of this case report and any accompanying images; the use of all health and medical information for scientific research and manuscript preparation was approved. A copy of the written consent is available for review by the Editor-in-Chief of this journal.

\section{Competing interests}

ZM is the hospital director at the Zan Mitrev Clinic. DP has received consultancy fees for her participation at an "acute care expert" meeting organized by Baxter Inc. The other authors declare that they have no competing interests.

Received: 3 December 2018 Accepted: 14 May 2019

Published online: 05 July 2019

References

1. Abu-Omar Y, Kocher GJ, Bosco P, Barbero C, Waller D, Gudbjartsson T, SousaUva M, Licht PB, Dunning J, Schmid RA, et al. European Association for CardioThoracic Surgery expert consensus statement on the prevention and management of mediastinitis. Eur J Cardiothorac Surg. 2017;51(1):10-29.

2. Ridder GJ, Maier W, Kinzer S, Teszler CB, Boedeker CC, Pfeiffer J. Descending necrotizing mediastinitis: contemporary trends in etiology, diagnosis, management, and outcome. Ann Surg. 2010;251(3):528-34. 
3. Laupland KB, Zygun DA, Doig CJ, Bagshaw SM, Svenson LW, Fick GH. Oneyear mortality of bloodstream infection-associated sepsis and septic shock among patients presenting to a regional critical care system. Intensive Care Med. 2005:31(2):213-9.

4. Prowle JR, Echeverri JE, Ligabo EV, Sherry N, Taori GC, Crozier TM, Hart GK, Korman TM, Mayall BC, Johnson PD, et al. Acquired bloodstream infection in the intensive care unit: incidence and attributable mortality. Crit Care. 2011;15(2):R100.

5. Polat G, Ugan RA, Cadirci E, Halici Z. Sepsis and septic shock: current treatment strategies and new approaches. Eurasian J Med. 2017;49(1):53-8.

6. Wilson JR, Limaye AP. Risk factors for mortality in patients with anaerobic bacteremia. Eur J Clin Microbiol Infect Dis. 2004;23(4):310-6.

7. Yang CC, Hsu PC, Chang HJ, Cheng CW, Lee MH. Clinical significance and outcomes of Clostridium perfringens bacteremia-a 10-year experience at a tertiary care hospital. Int J Infect Dis. 2013;17(11):e955-60.

8. Leal J, Gregson DB, Ross T, Church DL, Laupland KB. Epidemiology of Clostridium species bacteremia in Calgary, Canada, 2000-2006. J Inf Secur. 2008;57(3):198-203.

9. Salonen JH, Eerola E, Meurman O. Clinical significance and outcome of anaerobic bacteremia. Clin Infect Dis. 1998;26(6):1413-7.

10. Singer M, Deutschman CS, Seymour CW, Shankar-Hari M, Annane D, Bauer M, Bellomo R, Bernard GR, Chiche JD, Coopersmith CM, et al. The Third International Consensus Definitions for Sepsis and Septic Shock (Sepsis-3). JAMA. 2016;315(8):801-10.

11. Edmiston CE Jr, Krepel CJ, Seabrook GR, Jochimsen WG. Anaerobic infections in the surgical patient: microbial etiology and therapy. Clin Infect Dis. 2002;35(Suppl 1):S112-8.

12. Schuetz AN. Antimicrobial resistance and susceptibility testing of anaerobic bacteria. Clin Infect Dis. 2014;59(5):698-705.

13. Estrera AS, Landay MJ, Grisham JM, Sinn DP, Platt MR. Descending necrotizing mediastinitis. Surg Gynecol Obstet. 1983:157(6):545-52.

14. Endo S, Murayama F, Hasegawa T, Yamamoto S, Yamaguchi T, Sohara Y, Fuse K, Miyata M, Nishino H. Guideline of surgical management based on diffusion of descending necrotizing mediastinitis. Jpn J Thorac Cardiovasc Surg. 1999;47(1):14-9.

15. Ankawi G, Neri M, Zhang J, Breglia A, Ricci Z, Ronco C. Extracorporeal techniques for the treatment of critically ill patients with sepsis beyond conventional blood purification therapy: the promises and the pitfalls. Crit Care. 2018;22(1):262.

16. Thomas M, Moriyama K, Ledebo I. AN69: evolution of the world's first high permeability membrane. Contrib Nephrol. 2011;173:119-29.

17. Malard B, Lambert C, Kellum JA. In vitro comparison of the adsorption of inflammatory mediators by blood purification devices. Intensive Care Med Exp. 2018;6(1):12.

18. Feri M. "In vitro comparison of the adsorption of inflammatory mediators by blood purification devices": a misleading article for clinical practice? Intensive Care Med Exp. 2019;7(1):5.

19. Turani F, Candidi F, Barchetta R, Grilli E, Belli A, Papi E, di Marzio A, Falco M. Continuous renal replacement therapy with the adsorbent membrane oXiris in septic patients: a clinical experience [abstract]. Crit Care. 2013;17(Suppl 2):P63.

20. Shum HP, Chan KC, Kwan MC, Yan WW. Application of endotoxin and cytokine adsorption haemofilter in septic acute kidney injury due to Gramnegative bacterial infection. Hong Kong Med J. 2013;19(6):491-7.

21. Schädler D, Porzelius C, Jörres A, Marx G, Meier-Hellmann A, Putensen C, Quintel M, Spies C, Engel C, Weiler N, et al. A multicenter randomized controlled study of an extracorporeal cytokine hemoadsorption device in septic patients [abstract]. Crit Care. 2013;17(Suppl 2):P62.

22. Schadler D, Pausch C, Heise D, Meier-Hellmann A, Brederlau J, Weiler N, Marx G, Putensen C, Spies C, Jorres A, et al. The effect of a novel extracorporeal cytokine hemoadsorption device on IL-6 elimination in septic patients: a randomized controlled trial. PLoS One. 2017;12(10):e0187015.

23. Terayama T, Yamakawa K, Umemura Y, Aihara M, Fujimi S. Polymyxin B hemoperfusion for sepsis and septic shock: a systematic review and metaanalysis. Surg Infect. 2017;18(3):225-33.

24. Payen DM, Guilhot J, Launey Y, Lukaszewicz AC, Kaaki M, Veber B, Pottecher J, Joannes-Boyau O, Martin-Lefevre L, Jabaudon M, et al. Early use of polymyxin B hemoperfusion in patients with septic shock due to peritonitis: a multicenter randomized control trial. Intensive Care Med. 2015;41(6):975-84.

25. Bernardi MH, Rinoes H, Dragosits K, Ristl R, Hoffelner F, Opfermann P, Lamm C, Preissing F, Wiedemann D, Hiesmayr MJ, et al. Effect of hemoadsorption during cardiopulmonary bypass surgery - a blinded, randomized, controlled pilot study using a novel adsorbent. Crit Care. 2016;20:96.
26. Kobashi S, Maruhashi T, Nakamura T, Hatabayashi E, Kon A. The 28day survival rates of two cytokine-adsorbing hemofilters for continuous renal replacement therapy: a single-center retrospective comparative study. Acute Med Surg. 2019;6(1):60-7.

27. Levy MM, Evans LE, Rhodes A. The Surviving Sepsis Campaign bundle: 2018 update. Crit Care Med. 2018:46(6):997-1000.

28. Rhodes A, Evans LE, Alhazzani W, Levy MM, Antonelli M, Ferrer R, Kumar A, Sevransky JE, Sprung CL, Nunnally ME, et al. Surviving Sepsis Campaign: international guidelines for management of sepsis and septic shock: 2016. Intensive Care Med. 2017;43(3):304-77.

29. Tatum JM, Barmparas G, Ko A, Dhillon N, Smith E, Margulies DR, Ley EJ. Analysis of survival after initiation of continuous renal replacement therapy in a surgical intensive care unit. JAMA Surg. 2017;152(10):938-43.

30. Pasin L, Boraso S, Tiberio I. Initiation of renal-replacement therapy in the intensive care unit. N Engl J Med. 2016:375(19):1899-900.

31. Gaudry S, Hajage D, Schortgen F, Martin-Lefevre L, Pons B, Boulet E, Boyer A, Chevrel G, Lerolle N, Carpentier D, et al. Initiation strategies for renal-replacement therapy in the intensive care unit. N Engl J Med. 2016;375(2):122-33.

32. Zarbock A, Kellum JA, Schmidt C, Van Aken H, Wempe C, Pavenstadt $H$, Boanta A, Gerss J, Meersch M. Effect of early vs delayed initiation of renal replacement therapy on mortality in critically ill patients with acute kidney injury: the ELAIN randomized clinical trial. JAMA. 2016;315(20):2190-9.

33. Weaver $E$, Nguyen $X$, Brooks MA. Descending necrotising mediastinitis: two case reports and review of the literature. Eur Respir Rev. 2010; 19(116):141-9.

34. Diamantis S, Giannakopoulos H, Chou J, Foote J. Descending necrotizing mediastinitis as a complication of odontogenic infection. Int J Surg Case Rep. 2011;2(5):65-7.

35. Kocher GJ, Hoksch B, Caversaccio M, Wiegand J, Schmid RA. Diffuse descending necrotizing mediastinitis: surgical therapy and outcome in a single-centre series. Eur J Cardiothorac Surg. 2012;42(4):e66-72.

36. Lareyre F, Cohen C, Declemy S, Raffort J, Quintard H. A fatal aortic arch rupture due to descending necrotizing mediastinitis in a 24-year-old woman. Vasc Endovasc Surg. 2017;51(6):408-12.

37. Palma DM, Giuliano S, Cracchiolo AN, Falcone M, Ceccarelli G, Tetamo R, Venditti M. Clinical features and outcome of patients with descending necrotizing mediastinitis: prospective analysis of 34 cases. Infection. 2016;44(1):77-84.

38. Grundmann H, Glasner C, Albiger B, Aanensen DM, Tomlinson CT, Andrasevic AT, Canton R, Carmeli Y, Friedrich AW, Giske CG, et al. Occurrence of carbapenemase-producing Klebsiella pneumoniae and Escherichia coli in the European survey of carbapenemase-producing Enterobacteriaceae (EuSCAPE): a prospective, multinational study. Lancet Infect Dis. 2017;17(2):153-63.

39. Chumbler NM, Farrow MA, Lapierre LA, Franklin JL, Haslam DB, Goldenring JR, Lacy DB. Clostridium difficile toxin B causes epithelial cell necrosis through an autoprocessing-independent mechanism. PLoS Pathog. 2012;8(12):e1003072.

40. Engel A, Kern P, Kern W. Levels of cytokines and cytokine inhibitors in the neutropenic patient with a-hemolytic streptococcus shock syndrome. Clin Infect Dis. 1996;23(4):785-9.

41. Ronco C, Ricci Z, De Backer D, Kellum JA, Taccone FS, Joannidis M, Pickkers P, Cantaluppi V, Turani F, Saudan P, et al. Renal replacement therapy in acute kidney injury: controversy and consensus. Crit Care. 2015;19:146.

42. Hattori N, Oda S. Cytokine-adsorbing hemofilter: old but new modality for septic acute kidney injury. Ren Replace Ther. 2016;2(1):41.

43. Pickkers P, Vassiliou T, Liguts V, Prato F, Tissieres P, Kloesel S, Turani F, Popevski D, Broman M, Gindac CM, et al. Sepsis management with a blood purification membrane: European experience. Blood Purif. 2019:47(Suppl 3):1-9.

44. Di Paolo N, Gaggiotti E, Galli F. Extracorporeal blood oxygenation and ozonation: clinical and biological implications of ozone therapy. Redox Rep. 2005;10(3):121-30

45. Manoto SL, Maepa MJ, Motaung SK. Medical ozone therapy as a potential treatment modality for regeneration of damaged articular cartilage in osteoarthritis. Saudi J Biol Sci. 2018;25(4):672-9.

46. Prauchner CA. Oxidative stress in sepsis: Pathophysiological implications justifying antioxidant co-therapy. Burns. 2017;43(3):471-85.

\section{Publisher's Note}

Springer Nature remains neutral with regard to jurisdictional claims in published maps and institutional affiliations. 